Byzantion Nea Hellás No 34

\title{
MODALIDADES DEL MATRIMONIO TARDOANTIGUO Y ALTOMEDIEVAL EN BIZANCIO Y EL OCCIDENTE CRISTIANO
}

\section{MANUEL VIAL-DUMAS}

\section{Universitat Oberta de Catalunya y Universidad de Girona. España}

Resumen: En este trabajo se presenta una comparación de algunas cuestiones referidas al matrimonio en el Mediterráneo cristiano occidental y Bizantino. Se propone un paralelo entre las modalidades de matrimonio; en particular a través del juego de las variables que supone un matrimonio escrito y no escrito, con transferencia de bienes o sin transferencia de bienes.

Palabras clave: Historia del matrimonio - Derecho de familia - - Derecho de la alta Edad Media - Derecho bizantino - Derecho comparado-

\section{Forms of marriage in Byzantium and the Christian West during late antiquity and early Middle Ages}

Abstract: This paper presents a comparison between some issues related to marriage in Christian Mediterranean, in both the West and the Byzantine area. It is proposed a parallel between modes of marriage; in particular through the interplay of two variables: a written and unwritten marriage, and marriage with or without transfer of goods.

Keywords: History of marriage - Family law - Early Middle Ages Byzantine law - Comparative law

Recibido: 9.01.2015 - Aceptado: 6.03.2015

Correspondencia: Manuel Vial Dumas. E. mail: mviald@uoc.edu Doctor en derecho, especialista en historia del pensamiento jurídico, profesor de la Universitat Oberta de Catalunya y de la Universidad de Girona. España 
Manuel Vial D.: Modalidades del matrimonio tardoantiguo y altomedieval...

\section{Introducción}

T a comparación entre las instituciones jurídicas de la Cristiandad oriental y la occidental es útil en cualquier época. En la Antigüedad tardía, no obstante, resulta de particular interés, pues es posible observar el desarrollo paralelo de instituciones que tienen un origen común cercano y que se desenvuelven, hasta cierto punto, de forma independiente, en un lado y el otro.

En el presente trabajo pretendo presentar algunas cuestiones comunes a ambos en lo que respecta al matrimonio. En particular, analizo la distinción propia del derecho bizantino, por una parte, entre matrimonio escrito y no escrito y, por la otra, con transferencia de bienes o sin transferencia de bienes (y la combinación de estas variables), poniéndolas en paralelo con la realidad occidental. Todas estas comparaciones se hacen en particular sobre la base de la legislación imperial bizantina y la experiencia ibérica e itálica. No obstante, creo, que la mayoría de las conclusiones son extrapolables al resto de sociedades de la Cristiandad occidental altomedieval.

\section{El contexto del matrimonio}

Las crisis políticas, sociales y económicas, que terminaron por desmembrar la parte occidental del Imperio y cambiar profundamente la de oriente, provocaron también la simplificación de la vida social y económica del Mediterráneo, en especial entre el siglo V y el VIII ${ }^{1}$. Dicha simplificación determinó a su vez profundos cambios en la concepción y en el uso del derecho y la ciencia jurídica. El fenómeno que tradicionalmente en la historiografía occidental se ha llamado vulgarización ${ }^{2}$, en parte es la adaptación de la técnica jurídica a una sociedad cuyas estructuras

\footnotetext{
${ }^{1}$ Una de las pocas visiones panorámicas de todo el Mediterráneo en Wickham (2005).

${ }^{2}$ La denominación fue acuñada por Brunner (1880) Aunque tras las décadas ha ido tomando significados diversos. Una visión general del derecho de la época y que intenta superar el concepto de derecho romano vulgar puede verse en una obra de Paolo Gorssi (2007) p. 19 ss. especialmente escrita para historiadores no juristas.
} 
experimentaban una profunda crisis. El fenómeno no es solamente occidental, como habitualmente se presenta, en oriente sucede algo similar. A pesar de mantener su unidad política y de experimentar algunas décadas de gran esplendor, el Imperio de oriente, sobre todo después de Justiniano, se vio asolado también por crisis económicas, demográficas y sociales ${ }^{3}$. El derecho, como en occidente, en oriente también se simplifica y su práctica pierde la riqueza lingüística y científica que la caracterizara siglos antes. ${ }^{4}$

En este contexto, la ciencia jurídica en tanto disciplina separada, singular entre las artes liberales, prácticamente desaparece. Esto sucede primero en occidente y luego en oriente, de modo que el derecho escrito se reduce a la certificación de ese otro derecho mucho más importante contenido en la costumbre o a la conservación de las pocas partes de legislación imperial o de jurisprudencia que pueden ser útiles. El derecho consuetudinario reina en dicho período en el escenario de la villa, que es el contexto por excelencia de las relaciones sociales altomedievales en oriente y occidente cristiano ${ }^{5}$. El legislador (sea el emperador, un rey u otra autoridad civil o eclesiástica), cuando interviene en esa realidad, lo hace precisamente para intentar ordenar aquellas cuestiones urgentes, imprescindibles, prioritarias para el mantenimiento de la vida en común: el derecho de familia y el derecho penal.

No es extraño que así sea, el resto de las cuestiones jurídicas o bien son resueltas por la costumbre o bien ni siquiera se presentan. Es el caso de muchas instituciones pensadas para un mundo sofisticado, en el que existe un aparato político universal eficaz y en el que las relaciones comerciales entre distintos pueblos se encuentran activas.

Si revisamos algunos de los cuerpos normativos más emblemáticos veremos que son estos temas los que acaparan la atención y la acción de los legisladores tanto dentro como fuera del Imperio. Así, entre los longobardos

\footnotetext{
${ }^{3}$ Un panorama general en Haldon (1997).

${ }^{4}$ Troianos (2010)158-62 y (2011) p. 147 ss.

${ }^{5}$ En occidente son bastante conocidos los múltiples estudios sobre las circunstancias en que se desarrollaban las relaciones sociales, por eso señalo aquí alguna bibliografía importante sobre la cuestión en el mundo bizantino: Kaplan (1992); Laiou-Thomadakis (1977); Laiou (2002, pp. 311-75) y Lefort (2002, pp. 231-310).
} 
Manuel Vial D.: Modalidades del matrimonio tardoantiguo y altomedieval...

el Edicto de Rothario comienza regulando el matrimonio y los esponsales y, más tarde, Liutprando, mucho más influenciado por el pensamiento cristiano, dedicará un gran porcentaje de las disposiciones del Edicto al matrimonio, a los esponsales, a asegurar un mejor estatus a la mujer y a las relaciones patrimoniales en la familia. El resto de las normas, en una alta proporción, podrían calificarse como derecho penal ${ }^{6}$.

En Bizancio, cuando la gran crisis del Imperio que comenzara ya con la peste de Justiniano, la pérdida de provincias riquísimas como Egipto y Siria y el incesante ataque musulmán, se promulga la Ecloga de León III Isauro y Constantino $\mathrm{V}^{7}$. Como su nombre lo indica es una selección de aquellas normas más importantes, las imprescindibles para la sustentación jurídica del Imperio. León, igual que Rothario, dedica el primer y segundo título de la Ecloga a los esponsales y al matrimonio respectivamente y luego muchas otras reglas al derecho de familia y al derecho penal. El caso Ibérico es ligeramente diferente, pues los visigodos mantienen un arraigo más fuerte a la tradición textual tardoimperial, de modo que el Liber Iudiciorum dedica los primeros dos libros a una especie de constitución política del reino y a la administración de justicia, para luego regular y dedicar una delicada atención (los libros tercero y cuarto) al matrimonio y sus efectos patrimoniales ${ }^{8}$. No obstante, los visigodos también innovaron y cambiaron el marco jurídico de

${ }^{6}$ El Edicto de Rotario (en adelante Roth.) es de mediados del siglo VII, las leyes de Liutprando (en adelante Liut.) de principios del s. VIII. He consultado la edición de Friedrich Bluhme reproducida, traducida al italiano y comentada en Azzara y Gasparri (2005), Consúltese su interesante estudio preliminar.

${ }^{7}$ La Ecloga $(E \kappa \lambda o \gamma \eta \dot{\tau} \tau \tilde{\omega} v$ vó $\mu \omega v)$ data de mediados del siglo VIII y se presenta a sí misma como una selección de las leyes vigentes, por antonomasia las provenientes de la compilación justinianea. He consultado la edición de Burgmann (1983).

${ }^{8}$ El ímpetu de teólogos, moralistas, juristas sobre estas cuestiones no era un interés meramente retórico, al contrario, se enmarca dentro de una sociedad donde el matrimonio se instala en el mismo centro. Siglos después, en Castilla, las Siete Partidas, llenas de simbología y alegorías no dedican por casualidad la Cuarta Partida, la del centro, al matrimonio y la familia. No es sólo la realidad de esa época, las partidas son del siglo XIII, sino que es el resultado de un fenómeno que ya se observa en estos textos anteriores y que se refuerza en la medida que avanzamos hacia el fin del primer milenio. 
las relaciones familiares aunque sin deshacerse de la herencia romana, en una línea similar a la de bizantinos y longobardos.

Desde la época imperial tardía asistimos, pues, a un desplazamiento de las cuestiones matrimoniales, sucesorias y penales a un lugar preferente en las prioridades sociales de la época y, como reflejo de esto, pasan a constituir también parte central en la actividad legislativa. En estas obras se vislumbran algunas estructuras en lo referente al matrimonio que, como sostengo, pueden ponerse en paralelo de tal modo que un mundo jurídico como el altomedieval, tremendamente fragmentado y aparentemente disímil, adquiere cierta fisionomía común.

\section{Modalidades del matrimonio}

En el antiguo mundo romano no existía una forma única de celebración del matrimonio, pues para la existencia de un matrimonio bastaba con la vida en común que demostrase un ánimo de estar casados. Por eso eran tan importantes los signos externos, pues estos permitían diferenciar un matrimonio del concubinato. Que la mujer compartiera la dignidad de su marido, que asistiera con él a actos públicos, que se hubiera entregado una dote, que ella dirigiera los asuntos domésticos, en fin, todo aquello que permitiera entender sin lugar a dudas que un hombre había tomado a una mujer por esposa?

Una de esas manifestaciones externas que permitían inferir la existencia de un matrimonio era la de hacer transferencia de bienes entre las familias; la dote por parte de la mujer y, desde la época tardoimperial, la donatio propter nuptias, por parte del marido. Durante esta época, cuando dichas transferencias se llevaban a cabo, se asentó la costumbre de elaborar pactos que regularan el destino de dichos bienes (pacta de lucranda donatione $)^{10}$. Se trata de una manera de formalizar el vínculo con un acuerdo por escrito cuyo objeto normalmente más que declarar la existencia del

\footnotetext{
${ }^{9}$ Para el matrimonio romano hay una interminable bibliografía, una visión general y bien documentada en Treggiari (1993).

${ }^{10}$ García Garrido (1959, p. 409-12).
} 
Manuel Vial D.: Modalidades del matrimonio tardoantiguo y altomedieval...

matrimonio en sí, era la de regular los términos de la convivencia y las relaciones económicas entre los cónyuges y las familias de los cónyuges, tal como se hacía ya en la antigua Roma. Esto no obsta a que el matrimonio fuera celebrado además o conjuntamente mediante un rito religioso, por ejemplo.

Por otra parte, por no ser necesaria la redacción de acuerdos matrimoniales, no había trabas para que el matrimonio se constituyera sin escrituras ni solemnidad alguna. Podemos suponer que dichos matrimonios a menudo no implicaban transferencias de bienes entre los cónyuges, pues, como se ha dicho, los contratos matrimoniales tenían como fin principal establecer dichas relaciones patrimoniales entre las familias y las donaciones que se llevarían a cabo. En este caso, siguiendo la tradición romana, los cónyuges que viven juntos constituyen un matrimonio per affectum solum, sin pasar por las solemnidades de instrumentos dotales u otras formas rituales que le dieran publicidad. Esta forma de constituir el matrimonio debió haber sido común entre aquellos que no ostentaban alguna dignidad especial, pues, Justiniano hará obligatoria esta costumbre para los decorados con las máximas dignidades sobre la categoría de illustrious, a quienes estaba prescrita la celebración de acuerdos matrimoniales, exceptuados los dignatarios de pueblos bárbaros súbditos del emperador ${ }^{11}$.

Como venimos señalando esta forma de manifestar el consentimiento no se opone a otras como la celebración ritual (que desde el siglo III será poco a poco sinónimo de celebración eclesiástica) ni siquiera cuando la bendición de un sacerdote se imponga como necesaria a finales del primer milenio en oriente y ya entrado el segundo, en occidente ${ }^{12}$. De esta forma la tradición

${ }^{11}$ Véase: CI 5.17.11 [Codex Iustinianus ed. Krüger (1870)], Nov. 53.6; Nov. 117, 35. [Novelas de Justiniano, ed. Mommsen Th. - Krueger P. (ed.) (1877)].

${ }^{12}$ Fue el emperador León VI quién introdujo, en Bizancio, la ceremonia religiosa como única forma de celebración del matrimonio (Novela 89 [ed. Noailles (1944), traducidas al griego moderno con mejoras respecto de la traducción al francés por Troianos (2007)]. Adquiría así, la Iglesia, un control y una competencia cada vez más importante sobre la materia. En Occidente la evolución es diferente. El interés de la Iglesia y también del poder seglar por evitar la clandestinidad, el concubinato, la bigamia, etc., determinaron la preocupación por definir no sólo validez y efectos, sino también asegurar la publicidad de los matrimonios que garantizara el adecuado 
romana se perpetúa durante buena parte de la Edad Media, aunque poco a poco la concepción del matrimonio cambia para dejar de ser un hecho que se constata y pasar a ser un estado al que se accede mediante un acto, como la celebración religiosa, la escrituración u otras medidas de publicidad ${ }^{13}$.

\subsection{Matrimonio Engraphos y Agraphos}

El matrimonio puramente consensual (es decir sin formalidad como una celebración religiosa o los documentos matrimoniales en los que se pacta el destino y las condiciones de las donaciones nupciales) se encuentra claramente recogido en el Código de Justiniano. El Emperador señala que si alguien hubiera recibido a una mujer con intención de hacerla su cónyuge y con la aprobación de sus padres, debe considerarse firme el matrimonio entre ambos; aunque no existan ni instrumentos dotales, ni dote, porque los matrimonios no se contraen por las dotes, sino por el affectus ${ }^{14}$. A la misma tradición se incorpora el texto de la Ecloga de Léon III y Constantino V del año 741, que representa de alguna forma la culminación bizantina de esta tendencia. La Ecloga distingue tres tipos de matrimonio: en primer lugar un matrimonio solemne que consta por escrito ( $\gamma_{\gamma} \gamma \rho \alpha \varphi \circ \varsigma \gamma \alpha \dot{\alpha} \mu \varsigma \varsigma$ ), celebrado ante tres testigos y en que se deja constancia de las transmisiones patrimoniales

control de las uniones ilegítimas. Ese largo camino, no obstante, no significó la exigencia de una celebración ritual en particular, al menos no durante gran parte de la alta Edad Media: véase Vogel (1977, pp. 397-465) y Reynolds (2007, pp. 1-42) para mayor detalle de las formas de documentación véase también el resto de capítulos de dicho libro.

${ }^{13}$ Sobre la concepción cristiana del matrimonio véase una visión panorámica en Reynolds (1994).

${ }^{14}$ CI 5.17.11 Iubemus, ut, quicunque mulierem cum voluntate parentum aut, si parentes non habuerit, sua voluntate maritali affectu in matrimonium acceperit, etiamsi dotalia instrumenta non intercesserint, nec dos data fuerit, tanquam si cum instrumentis dotalibus tale matrimonium processisset, firmum coniugium eorum habeatur; non enim dotibus, sed affectu matrimonia contrahuntur. Otras fuentes en n. 11. 
Manuel Vial D.: Modalidades del matrimonio tardoantiguo y altomedieval...

entre las familias. En segundo lugar, el matrimonio no escrito (ă $\gamma \rho \alpha \varphi \circ \varsigma$ $\gamma \alpha \dot{\alpha} \mu \varsigma \varsigma$ ), para el cual es necesario, además de la buena fe y del consentimiento de los cónyuges y sus padres, la bendición de la Iglesia o bien una declaración ante testigos. Por último, como una modalidad del matrimonio no escrito, la Ecloga también contempla una forma residual de constitución del matrimonio: si un hombre introduce a una mujer en su casa, le encarga su dirección y mantiene relaciones sexuales con ella, debe considerarse casado ${ }^{15}$.

Esta formulación no es más que el desarrollo de la legislación justinianea y su tendencia a someter el concubinato a los mismos efectos del matrimonio $^{16}$. En ella subyacen los principios fundamentales del matrimonio romano, la convivencia y el ánimo, como suficientes para considerarlo constituido. En este sentido, la regulación de la forma de celebración del matrimonio en la Ecloga no plantea mayor originalidad respecto de la tradición justinianea, salvo por la importancia que le otorga a la bendición eclesiástica como constitutiva del mismo y la presencia que tiene el matrimonio no escrito en su redacción. En efecto, el matrimonio no escrito recibe mayor tratamiento poniendo así de manifiesto el peso que en la práctica dicho matrimonio debió adquirir en todo el Imperio. Más tarde, en la Ecloga privata aucta, la presencia y valor del matrimonio no escrito parece aumentar todavía más ${ }^{17}$.

Lo interesante, pues, de esta distinción bizantina es que por regla general estas diversas modalidades de matrimonio llevan aparejadas un

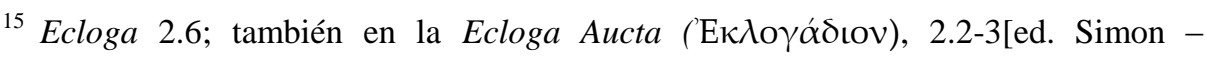
Troianos (1977)].

${ }^{16}$ Véase Patlagean (1977 p. 114 ss.)

${ }^{17}$ La data de la EPA [ed. Simon - Troianos (1977)] no es del todo clara, no obstante probablemente no sea anterior al s. IX, véase Troianos (2011, pp. 268-9). En ella el matrimonio no escrito no aparece subordinado al escrito, como sucede en la Ecloga. Al contrario, el autor parece considerarlo la forma primera, más simple, igual en dignidad y valor y accesible para personas de toda condición, EPA 2.2; Goria (1980, p. 52). Es probable que la actitud del legislador hacia el matrimonio no escrito fuera experimentando una evolución: en la obra de Justiniano aparece marginalmente, en la Ecloga tiene una presencia mayor pero aun subordinada, en la EPA en cambio, es una forma que ha sido igualada a la escrita. 
régimen patrimonial distinto. En este trabajo no entraré al análisis de dichos regímenes y su funcionamiento, baste con decir aquí que uno supone transferencia de bienes entre las familias de origen o entre los cónyuges (como por ejemplo, la dote, la donatio propter nuptias u otras donaciones similares que se presentan durante la Edad Media tanto en el oriente como en el occidente cristiano) y el otro, que suele acompañar al matrimonio no escrito, no las supone ${ }^{18}$.

${ }^{18}$ En dos trabajos que preparo me referiré concretamente a estos regímenes diferenciando el matrimonio que supone transferencia de bienes entre los cónyuges y sus familias y el que no las contempla. En el primero lo haré con exclusiva referencia al ámbito bizantino y, en el segundo, intentaré una comparación con alguno de los reinos de la Europa latina. 
Manuel Vial D.: Modalidades del matrimonio tardoantiguo y altomedieval...

\subsection{Matrimonio con y sin transferencia de bienes}

Es claro que, a pesar de que la Ecloga distingue entre el matrimonio escrito y no escrito, no se trata ésta de una distinción teórica. No es el matrimonio en sí lo que se celebra por escrito, sino que ésta es la forma por la que el ánimo de estar casados se externaliza. Lo que en realidad se esconde detrás de la distinción práctica es la diferencia entre un matrimonio con transferencia de bienes y uno en el que no se producen dichas transferencias.

En efecto, en la percepción del legislador imperial la transferencia de bienes en forma de aportaciones nupciales da lugar normalmente a un acto escrito. Dicha transferencia determina que las relaciones patrimoniales entre los cónyuges y entre sus familias de origen tengan una ordenación distinta de aquellos matrimonios en los que no se produce dicha transferencia. En los primeros habrá que elaborar un documento que detalle el intercambio económico de manera singular, mientras que en los segundos podrá pactarse genéricamente un régimen o simplemente omitir cualquier pacto escrito asumiendo que la costumbre o el régimen legal operan para ese caso.

En definitiva, para sistematizar dentro de lo que cabe, observamos una categoría de matrimonio que, si bien tienen la misma validez que los otros en cuanto vínculo entre marido y mujer, es la versión más completa de dicha unión. Esto es así pues supone una celebración solemne compuesta por la escrituración y a menudo por alguna celebración religiosa, testigos y la transferencia de bienes entre las familias que ayudan a proveer de sustancia patrimonial y, con ello, de estabilidad al matrimonio. Asimismo apreciamos una segunda categoría que carece de alguno de estos elementos. Esta segunda categoría puede ser un matrimonio en el que se verifiquen celebraciones rituales pero no escrituración, o bien, escrituración pero no transferencia de bienes. Por último, una categoría residual en la que lo único que existe es el elemento esencial del matrimonio, es decir la affectio maritalis, mientras faltan las solemnidades y la transferencia de bienes. El matrimonio escrito y con transferencias de bienes es la expresión social y jurídicamente más perfecta del matrimonio. La existencia de ambos elementos es complementaria, pues cuando se realizan las transferencias surge la necesidad 
de regular el destino de los bienes y establecer con claridad su procedencia. Como se observa en las disposiciones imperiales citadas, esta versión del matrimonio está prescrita para las altas dignidades y es de suponer que serán esos mismos matrimonios en los que se lleven a cabo transferencias de bienes de importancia y por lo tanto se proceda a su escrituración, de lo contrario sería difícil resguardar el patrimonio de las familias de origen y de los cónyuges ante una posible disolución del vínculo matrimonial.

\subsection{La Europa Latina}

En la Europa latina una distinción de este tipo no se presenta tan clara como en la legislación imperial bizantina. No obstante, el matrimonio contraído sin solemnidad alguna era normalmente válido. Hay normas entre los visigodos, por ejemplo, que castigan el matrimonio por rapto, sin embargo, fuera de esta hipótesis, un matrimonio puramente consensual era perfectamente admitido. En efecto, la Iglesia, en un principio, mantuvo una cierta indiferencia ante el ritual matrimonial dejándolo a lo que establecieran los usos locales, siempre que se diera el consentimiento de los cónyuges públicamente $^{19}$. Sin embargo, a finales del primer milenio, en oriente y occidente, la preferencia por la celebración eclesiástica fue cada vez más intensa; además se expidieron diversas recomendaciones para que en las bodas se observara un comportamiento honesto, no degenerara en impudicias y participara un clérigo, así lo recomendaba el Papa Nicolás I en 866. No obstante, tras su recomendación en la que describe todos los actos, donaciones, y rituales con los que normalmente se celebra un matrimonio, señala que la omisión de dichas formalidades no afecta al vínculo, pues la celebración formal es costosa y aquellas personas que no puedan permitirse dicho despliegue necesitan sólo del consenso para celebrar su matrimonio ${ }^{20}$.

${ }^{19}$ Véase Toubert (2006b, p. 232 ss.). También Gaudemet (1993, p. 63 ss.).

${ }^{20}$ Nicolás I, Responsa ad consulta Bulgarorum. Epist. 99, c.3 en MGH Espistolae 6, Epistolae Karolini aevi 4, p. 570, líneas 16-21. Véase el trabajo de Laiou (1985, pp. 189-201) en el que analiza los responsa del Papa Nicolás I a las 106 preguntas que le enviara el rey de los búlgaros, Boris. Véase también Toubert (2006) pp. 278 ss y Reynolds (2007, pp. 1-6). Asimismo conocemos medidas que incentivaban actos 
Manuel Vial D.: Modalidades del matrimonio tardoantiguo y altomedieval...

En este intento por aumentar el control sobre el matrimonio, aunque no se impone una forma específica o la necesidad del clérigo (en occidente será sólo en el Concilio de Trento cuando se exija), sí se intenta quitar validez a las uniones clandestinas o violentas, porque, además de las implicaciones morales que consideraban los teólogos y canonistas, daban lugar a matrimonios que alteraban las estrategias patrimoniales de las familias. Es, pues, sobre todo desde principios del segundo milenio cuando los requisitos de publicidad del matrimonio se intensifican y la bendición eclesiástica se hace cada vez más necesaria hasta ser un requisito imprescindible. Aún así, un porcentaje de la población, ese que tiene en mente el Papa Nicolás en sus respuestas, seguirá estando por un buen tiempo relativamente ajeno a este matrimonio solemne ${ }^{21}$.

Todo este proceso forma parte de las mismas dinámicas que dieron a la Iglesia un control más efectivo sobre el matrimonio y contribuyeron a la ampliación de los grados de parentesco prohibidos ${ }^{22}$. Antes de que eso suceda, un matrimonio podía celebrarse sin formalidades, sin ceremonias religiosas y, por supuesto, sin constancia escrita, como en Bizancio. La falta de escrituración, ni en Bizancio ni en la Europa latina estaba reñida con la ceremonia religiosa, era común que en una boda compareciesen testigos y bendición sacerdotal, pero que no se escriturara. Asimismo era posible que el matrimonio se celebrara sin la comparecencia de testigos y sin bendición eclesiástica, sino por el simple consentimiento de los cónyuges. Las distinciones que con tanta claridad hace la Ecloga son, según mi juicio,

previos al casamiento, una de las más conocidas es la consignada en las conclusiones del IV Concilio de Letrán de 1215 que exigía que se realizaran las amonestaciones, consistentes en formalidades que daban publicidad al matrimonio a fin de sacar a la luz los impedimentos para celebrarlo. Sin embargo, ésta y otras disposiciones que tenían fines similares, no establecían que la celebración pública de una boda ante la iglesia fuera un requisito necesario, al menos no desde un punto de vista civil, pero se acercan bastante y allanan el camino para su posterior exigencia (Gaudemet (1993) pp. 263 ss; Duby (1988, pp. 19 ss.); Cristellon (2004, pp. 33-40). Asimismo, la Iglesia promoverá el uso de la dote de la mujer al contraer matrimonio, reforzando así no sólo su publicidad, sino también su carácter contractual.

${ }^{21}$ Véase Coontz (2006, pp. 143-65).

${ }^{22}$ Sobre esta cuestión en Bizancio véase un próximo trabajo: Vial (2015). 
aplicables a toda la Cristiandad: por un lado un matrimonio escrito con todas las solemnidades, por otro, uno no escrito que puede celebrarse ante un sacerdote, ante testigos o ambos y, por último, una hipótesis residual en que ninguno de estos elementos está presente, salvo el consenso de los cónyuges. Todos los matrimonios tienen igual valor, aunque normalmente en los de la primera categoría es en los que se realizan transferencias de bienes. En otras palabras, se trata de la supervivencia de la idea romana del matrimonio en comunión con las ideas cristianas que lo hacían además prácticamente indisoluble y, poco a poco, dependiente de un acto inicial.

De ahí que la constitución del matrimonio tiene escasa importancia en las leyes bizantinas, visigodas o longobardas. Lo que importa es la ordenación patrimonial, es allí donde aparece el matrimonio en la legislación secular. Y el que figura por excelencia es aquel en el que se realizan transferencias patrimoniales entre las familias y del que normalmente se deja testimonio escrito $^{23}$. Como hemos señalado, la distinción entre matrimonio escrito y no escrito no constituye una taxonomía del matrimonio, se trata de una distinción de orden práctico que se manifiesta como una consecuencia casi espontánea de la posibilidad, siempre contingente, que tenían las familias de hacer o no transferencias patrimoniales con ocasión del matrimonio o de la necesidad de ordenar el destino de los bienes que los cónyuges pudieran adquirir. Así, una familia pobre que no está en condiciones de hacer una aportación nupcial, podrá sin mayor inconveniente prescindir de la forma escrita del matrimonio, pues nada tiene que regular si por la costumbre o la legislación del lugar hay un destino predefinido para los bienes de la familia nuclear. Mientras que una familia más pudiente, capaz de realizar dichas transferencias, por muy escasa y dificultosa que sea la práctica de la escrituración de los acuerdos, intentará poner sobre papel al menos las reglas básicas que establecen el origen y guiarán el destino de dichos bienes en ese caso en concreto.

\footnotetext{
${ }^{23}$ Principalmente por las cuestiones patrimoniales se regula el matrimonio en la legislación visigoda o longobarda. Tampoco en la legislación estatutaria en Italia y la foral en la península ibérica hay gran tratamiento de otras cuestiones que no sean las patrimoniales.
} 
Manuel Vial D.: Modalidades del matrimonio tardoantiguo y altomedieval...

En el caso Longobardo la transferencia patrimonial por excelencia era la morgengabe y, en un lugar secundario, el faderfio. Rotario aún concebía la morgengabe, el regalo que hacía el marido a la mujer la mañana siguiente de la boda, como una donación de bienes muebles para el uso personal de la mujer, no como una aportación al matrimonio que suponga transferencia de bienes al modo de la donatio propter nuptias romana ${ }^{24}$. Más tarde, no obstante, el rey Liutprando establecía un límite de una cuarta parte de los bienes del constituyente para dicha donación y establecía que la morgengabe o morgincap debía entregarse el mismo día de las nupcias. De esta manera la asimilaba a la donación romana. Además señalaba que dicha donación podía consistir en bienes inmuebles, debía ser confirmada testimonialmente, enseñada su substancia a los parientes al día siguiente de la boda y debía constar por escrito ${ }^{25}$. Las normas que mandan la exhibición y la entrega de la morgengabe, además de su escrituración, se refieren según mi entender a un matrimonio solemne equiparable al engraphos gamos bizantino. La voluntariedad de la donación queda manifiesta en las propias palabras de Liutprando quien, antes de referirse a las reglas mencionadas, comienza diciendo: "Si algún longobardo quiere dar la morgingab a su mujer" 26 . Probablemente en dichas bodas con transferencia de bienes fuera más común la constitución del faderfio, que en un principio no era más que el ajuar de la novia, pero que adquirió con el tiempo una fisionomía más similar a la de una aportación nupcial como la dote, en especial en los matrimonios $\operatorname{aristocráticos~}^{27}$. Más tarde, los diversos regímenes patrimoniales que se verifican en la Península tienden a unificarse. En especial después de que la dote de la mujer volviera a ser la donación principal en el matrimonio. En ese momento es cuando la distinción entre un matrimonio con transferencia de bienes y uno sin transferencia de bienes se hace más patente ${ }^{28}$.

\footnotetext{
${ }^{24}$ Roth. 182, 199, 200, 216

${ }^{25}$ Liut 7 de 717 y Liut. 103 de 728

${ }^{26}$ Liut 7 de 717

${ }^{27}$ Sobre las donaciones nupciales véase Bougard (2002, pp. 57-95)

${ }^{28}$ La unificación se da sobre todo con un régimen de donaciones mutuas donde la dote de la mujer es la donación principal y la del marido es accesoria (por lo que recibe, entre otros, el nombre de antifactum). Para una visión general de estos
} 
En la legislación visigoda, por su parte, es posible encontrar rastros de una distinción similar. En efecto, el acto de constitución de la dote (normalmente masculina) podía perfeccionarse en un documento o bien ante testigos $^{29}$, aunque se aconsejaba su constitución por escrito ${ }^{30}$. Varios autores han considerado que la entrega de dote no era un requisito necesario para la constitución del matrimonio, aunque sí servía, como ya en la antigua Roma, para distinguir la unión matrimonial de otras como el concubinato ${ }^{31}$. Ervigio, por su parte, reprobó la omisión de la constitución de la dote en las bodas nobles, lo que da más argumentos a esa postura. Tradicionalmente, desde que E. de Hinojosa lo planteara así, se considera que esas bodas nobles son las bendecidas por la Iglesia ${ }^{32}$. La cuestión ya había sido planteada por Cárdenas que creía o bien que se trataba de dichas bodas o bien, de las bodas de personas nobles ${ }^{33}$. Si creemos que las bodas nobles son aquellas celebradas dentro del círculo de las altas dignidades, es lógico pensar que en aquellas bodas no sólo se perfeccionara una efectiva transferencia de bienes en forma de dote masculina, femenina o bien de donaciones reciprocas, sino también que se celebraran por escrito, mientras que muchas otras, no. En la Península Ibérica, como en Italia, la pluralidad en este ámbito es inmensa durante la alta Edad Media, sin embargo también tienden a asentarse algunas formas comunes, algunas de ellas basadas en la misma lógica que en Italia y que supondrán el reflote de la dote de la mujer como donación principal y la

regímenes en Italia. di Renzo Villata (1995, pp. 492-505); Vismara (1988, pp. 141189); Owen Hughes (1996, pp. 34-43), Aunque ya en la época comunal Bellomo (1961). El análisis de las formas que suponen transferencia de bienes y las que no en Italia la reservo para un próximo trabajo.

${ }^{29}$ Bermejo Castrillo (2001, p. 102)

${ }^{30}$ LV. 3.1.9 Recesvinto [Lex Visigotorum [ed. Zeumer, 1902]

${ }^{31}$ Véase Bermejo Castrillo (1996, p. 105); López Nevot (1998, p. 29), véase también la bibliografía allí citada, en especial García Garrido (1959, p. 422)

${ }^{32}$ Hinojosa (1955, p. 356).

${ }^{33}$ Cárdenas (1884, p. 15 ss.). 
Manuel Vial D.: Modalidades del matrimonio tardoantiguo y altomedieval...

reducción de la donación del marido a un aporte accesorio. Por otra parte permanecerán vigentes formas que no suponen transferencias de bienes ${ }^{34}$.

Es cierto, sin embargo, que en Italia, durante la alta Edad Media, se observan pactos matrimoniales escritos que no suponen una transferencia de bienes, tal es el caso, por ejemplo del pacto de medietas, en que los cónyuges dividían por mitades sus bienes presentes y futuros y los cedían al otro cónyuge generando así una verdadera comunidad ${ }^{35}$. Sin embargo, parece ser que estos pactos buscan dar un régimen que no encuentra un respaldo legal, es decir que, para que funcione, debe hacerse expresamente. Lo mismo puede observarse en el caso hispánico. Allí se encuentra muy tempranamente algunas fórmulas visigóticas que, mediante el pacto de los cónyuges, generan un régimen económico del matrimonio, la mayoría suponen alguna transferencia de bienes pero las hay también que posponen dicha transferencia para el futuro o incluso para después de la muerte del marido; otros pactos, ya en época posterior, servían también para constituir comunidades lo que permite pensar que no había una transferencia de bienes al momento del matrimonio ${ }^{36}$. Estos pactos en algunos casos, por su repetición y reconocimiento, terminan formando un verdadero régimen consuetudinario e incluso legal; lo que significa a la postre que el pacto escrito sea innecesario, aunque siga celebrándose. Es el caso, por ejemplo, de los dos regímenes más frecuentes en Sicilia, el matrimonio alla graeca y alla latina, uno que implicaba necesariamente escrituración y transferencia de bienes y, el otro, que no implicaba dichas transferencias y que podía entenderse que operaba por la costumbre de modo subsidiario generando una comunidad de bienes familiar y que era propio de las gentes más humildes ${ }^{37}$.

${ }^{34}$ Cfr. Vismara (1988); para distintos tipos de pactos en la península Ibérica Font Rius (1954, pp. 191-244); para la evolución del régimen de bienes en Castilla Bermejo Castrillo (2001); Collantes de Terán (1997) y Gámez Montalvo (1998).

${ }^{35}$ Leicht (1933, pp. 94 ss.).

${ }^{36}$ Para estos pactos véase Font Rius (1954, pp. 207 ss.).

${ }^{37}$ Sobre estos regímenes véase Romano (1998, pp. 211 ss). También Romano (1994, pp. 89 ss.). 
Lo interesante no es por tanto que exista un matrimonio escrito y otro no escrito, cuestión que, como hemos dicho, no es más que una consecuencia, una manifestación de la existencia de regímenes patrimoniales distintos para los matrimonios de una clase u otra. De modo que bien podría reconstruirse el patrón de intercambio visigodo y longobardo en paralelo al bizantino: por un lado el matrimonio escrito (engraphos gamos), normalmente con transferencia de bienes y asociado a los sectores más ricos de la sociedad (aunque pueda celebrarse por escrito un matrimonio sin transferencia de bienes simplemente como testimonio de sus celebración), por el otro, el matrimonio no escrito (agraphos gamos) normalmente sin transferencia de bienes y, por último, como hipótesis residual del matrimonio no escrito, el puramente consensual. La pregunta que subsiste y que debe ser objeto de una investigación separada, es si el complejo sistema económico matrimonial de las tres regiones del Mediterráneo cristiano tiene elementos estructurales comunes o si se trata, por el contrario, de sistemas totalmente independientes.

\section{CONCLUSIONES}

Antes de que la celebración eclesiástica se imponga como forma de constituir el matrimonio, tanto en el oriente como en el occidente cristiano podemos ver cómo se proyectan las costumbres tardoantiguas y se desarrollan de forma espontánea y paralela, en especial en lo que se refiere al modo en que se celebra un matrimonio y sus consecuencias económicas. La Ecloga isáurica nos brinda un punto de partida para hacer una la taxonomía del matrimonio bizantino. De su texto se desprenden las dos variables fundamentales que jugarán un papel a la hora de definir las modalidades del matrimonio

La primera distinción es entre matrimonio escrito y no escrito. La segunda entre matrimonio con o sin transferencia de bienes entre los cónyuges. Ambas son distinciones de orden práctico y complementarias.

El matrimonio escrito, como es lógico, es la forma por excelencia del matrimonio que supone transferencia de bienes entre las familias de origen de los cónyuges. En ese acto escrito, que no es más que una expresión del 
Manuel Vial D.: Modalidades del matrimonio tardoantiguo y altomedieval...

matrimonio y no un requisito de validez, se ordena el destino de dichos bienes y se constituye prueba de su transferencia.

También es posible apreciar matrimonios escritos en que probablemente esas transferencias no se contemplen, de hecho esa escrituración tiende a convertirse en un régimen genérico que regula el destino de los bienes futuros que logren adquirir los cónyuges, e incluso en un régimen legal. En el matrimonio no escrito, además de faltar la escrituración, puede estar o no presente la transferencia de bienes, pero siempre existe al menos la comparecencia de testigos o la bendición eclesiástica, en fin, medidas de publicidad que marcan el comienzo del matrimonio.

Por último, el matrimonio no escrito puede presentarse como hipótesis residual que está en la frontera del concubinato y que consiste en el matrimonio que existe simplemente por consenso de los cónyuges y que prescinde de todos los otros elementos.

Esos matrimonios no escritos, por regla general, no suponen transferencia de bienes entre las familias, sino que se acogen a una ordenación genérica con el fin de regular el destino del patrimonio familiar que eventualmente se forme. Esta forma de entender el matrimonio puede ser trasladable también al lado occidental del Mediterráneo cristiano, en especial, como hemos hecho, al ámbito de la península Itálica e Ibérica.

A través de la ordenación económica del matrimonio y las normas seculares que le daban contenido, puede verse cómo estos mismos elementos, la escrituración, la bendición eclesiástica, la transferencia de bienes y en general la publicidad de la unión, podían sumarse al afecto para definir distintas modalidades de matrimonio.

La validez del mismo no está en cuestión, pero los regímenes económicos que tienen las dos categorías de matrimonio, es decir, el escrito con trasferencia de bienes y el no escrito sin transferencia de bienes, son distintos.

Estos regímenes económicos del matrimonio, que se presentaron por todo el Mediterráneo de maneras muy diversas, podrían tener una estructura 
similar, al fin y al cabo esa similitud es relativamente acusada entre los reinos de Occidente. Pero también podrían tenerla con el oriente cristiano. En todo caso, ese será el objeto de otra investigación.

\section{REFERENCIAS BIBLIOGRÁFICAS}

AZZARA, C. Y GASPARRI, S. (2005) Le leggi dei Longobardi. Storia, memoria e diritto di un popolo germanico. Segunda edición. Roma: Viella.

BELLOMO, M. (1961) Ricerche sui rapporti patrimoniali tra coniugi, contributo alla storia della famiglia medievale. Milano: Giuffrè.

BERMEJO CASTRILLO, M. (1996) Parentesco, matrimonio, propiedad y herencia en la Castilla altomedieval. Madrid: Universidad Carlos III de Madrid.

BERMEJO CASTRILLO, M. (2001) "Transferencias patrimoniales entre los cónyuges por razón del matrimonio en el derecho medieval castellano", en De la Iglesia, J. (edit.), La familia en la Edad Media: XI Semana de Estudios Medievales, Nájera, del 31 de julio al 4 de agosto de 2000. Logroño: Instituto de Estudios Riojanos. p. 93-150.

BOUGARD, F. (2002) "Dot et douaire en Italie centro-septentrionale, VIIIeXIe siècle: un parcours documentaire", en Bougard, François, Feller, Laurent y Le Jan Régine, Dots et dounaires dans le haut Moyen Âge. Roma : École française de Rome, pp. 57-95.

BRUNNER, H. (1880) Zur Rechtsgeschichte der römischen und germanischen Urkunde. Berlin.

BURGMANN, L. (1983) Ecloga: das Gesetzbuch Leons III. und Konstantinos $^{\prime} V$. Frankfurt a. M.: Löwenklau-Gesellschaft. 
Manuel Vial D.: Modalidades del matrimonio tardoantiguo y altomedieval...

CARDENAS, F. (1884) "Ensayo histórico sobre la dote, arras y donaciones esponsalicias desde los orígenes de la legislación española hasta nuestros días", en EL MISMO, Estudios Jurídicos II. Madrid: Estab. tip. de P. Núñez, pp. 5-62.

COLLANTES DE TERÁN, M. J. (1997) El régimen económico del matrimonio en el derecho territorial castellano. Valencia: Tirant lo Blanch.

COONTZ, S. (2006) Historia del matrimonio. Cómo el amor conquistó el mundo, Trad. Alcira Bixio Barcelona, Gedisa).

CRISTELLON, C. (2004) "La percezione del matrimonio prima del Concilio di Trento (Venezia, 1420- 1545), Popolazione e storia 2: pp. 33-40. También en versión inglesa: (2008) "Marriage and Consent in Pretridentine Venice: Between Lay Conception and Ecclesiastical Conception, 1420-1545", The Sixteenth Century Journal 39: pp. 389418.

DI RENZO VILLATA, G. (1995) "Persone e famiglia nel diritto medievale e moderno", en Digesto IV, Discipline privatistiche. Turin: Utet, pp. 457527.

DUBY, G. (1988) "Il matrimonio nella società dell'Alto Medioevo" en Duby, G. Medioevo maschio: amore e matrimonio, Trad. Maria Garin, primera edición. Roma: Laterza, pp. 5-25. La versión original es francesa y apareció en un volumen interesantísimo dedicado al matrimonio altomedieval: Duby, G. (1977) "Le mariage dans la société duhaut Moyen Âge occidental”, en VVAA. Il matrimonio nella società altomedievale, Settimane di Studio del Centro Italiano di Studi sull'alto Medioevo 24. Spoleto: Centro italiano di studi sull' alto medioevo, pp.13-39.

FONT RIUS, J. M. (1954) "La ordenación paccionada del régimen matrimonial de bienes en el derecho medieval hispánico", Anales de la Academia Matritense del Notariado 8, pp. 191-244.

GÁMEZ MONTALVO M. F. (1998) Régimen jurídico de la mujer en la familia castellana medieval. Granada: Editorial Comares.

GARCÍA GARRIDO, M. (1959) "El régimen jurídico del patrimonio uxorio en el derecho romano-visigótico", Anuario de historia del derecho español 29: pp. 389-446. 
GAUDEMET J. (1993) El matrimonio en Occidente, Trad. Barberán, M. y Trapero, F. Madrid: Taurus

GORIA, F. (1980) Tradizione romana e innovazioni bizantine nel diritto privato dell'Ecloga privata aucta. Frankfurt a. M.: Klostermann.

GROSSI, P. (2007) Europa y el derecho. Barcelona: Crítica.

HALDON, J. (1997) Byzantium in the seventh century: the transformation of a cultura, edición revisada. Cambridge: Cambridge University Press.

HINOJOSA, E. (1955) "Sobre la condición de la mujer casada en la esfera del Derecho civil (Discurso leído en su recepción en la Real Academia de Ciencias Morales y Políticas, el 26 de mayo de 1907)”, en EL MISMO, Obras, II. Madrid: Ministerio de Justicia y Consejo superior de investigaciones científicas.

KAPLAN, M. (1992) Les Hommes et la terre à Byzance du VIe au XIe siècle. París: Publications de la Sorbonne.

KRÜGER, P. (1870) Codex Iustinianus. Berlin: Weidmann.

LAIOU-THOMADAKIS A. (1977) Peasant Society in the Late Byzantine Empire. New Jersey: Princeton University Press.

LAIOU, A. (1985) "Consensus facit nuptias - Et non: Pope Nicholas I's 'Responsa' to the Bulgarians as a Source for Byzantine Marriage Customs", Rechtshistorisches Journal 4: pp. 189-201. Reimpreso en (1992) Gender, society and economic life in Byzantium. Aldershot: Variorum, pp. 189-201.

LAIOU, A. (1998) "Marriage prohibitions, marriage strategies, and the dowry in thirteenth-century Byzantium", en Beaucamp, J. y Dagron, G. (Edit.) La transmission du patrimoine: Byzance et l'aire méditerranéenne. Paris: De Boccard, pp. 129-160.

LAIOU, A. (2002) "The Agrarian Economy, Thirteenth-Fifteenth Centuries "en Laiou, A (ed.), The Economic History of Byzantium from the Seventh Trough the Fifteenth Century. Washington DC.: Dumbarton Oaks Studies, pp. 311-375.

LEFORT, J. (2002) "The rural economy, Seventh-twelfth centuries", en Laiou, A (ed.), The Economic History of Byzantium from the Seventh Trough the Fifteenth Century. Washington DC.: Dumbarton Oaks Studies, pp. 231-310. 
Manuel Vial D.: Modalidades del matrimonio tardoantiguo y altomedieval...

LEICHT, P. S. (1933) Il Diritto privato preirneriano. Bologna: N. Zanichelli.

LEVEROTTI, F. (2005) Famiglia e Instituzioni nel Medioevo italiano. Roma: Carocci.

LÓPEZ NEVOT, J. A. (1998) La aportación marital en la Historia del Derecho medieval. Almería: Universidad de Almería.

MOMMSEN TH. - KRUEGER P. (Ed.) (1877) Corpus Iuris Civilis, Berlín.

NOAILLES, P. (1944) Les nouvelles de Léon VI le Sage. Paris: Soc. d'édition Les Belles Lettres.

OWEN HUGHES, D. (1996) "Il Matrimonio nell'Italia medievale" en De Giorgio, M. y Klapisch-Zuber, C. (Edit.), Storia del matrimonio. Roma: Laterza, pp. 1-15.

PATLAGEAN, É. (1977) Pauvreté économique et pauvreté sociale à Byzance, $4 e-7 e$ siècles. París : Mouton.

PETOT, P. (1992) Histoire du droit privé français. La Famille. París: Loysel.

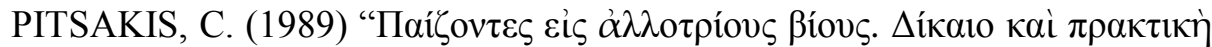

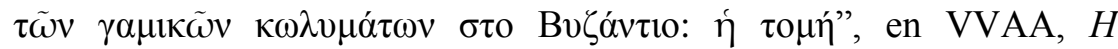

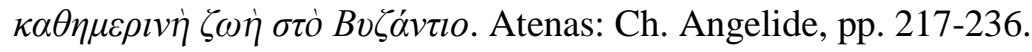

REYNOLDS, P. (1994) Marriage in the Western Church: The Christianization of Marriage During the Patristic and Early Medieval Periods. Leiden: E.J. Brill.

REYNOLDS, PHILIP (2007) "Marrying and Its Documentation in PreModern Europe: Consent, Celebration, and Property", en Reynolds, P. y Witte, J. (Edit.), To Have and to Hold: Marrying and its Documentation in Western Christendom, 400-1600. Cambridge: Cambridge University Press, pp. 1-42.

ROMANO, A. (1994) Famiglia, successioni e patrimonio familiare nell'Italia medievale e moderna. Torino: Giappichelli.

ROMANO, A. (1998) "Successioni «mortis causa» e patrimoni familiari nel Regno di Sicilia, secoli XIII-XVI", en Beaucamp, J. y Dagron, G., La transmission du patrimoine : Byzance et l'aire méditerranéenne. Paris: De Boccard, pp. 211-245. 
SIMON, D. Y TROIANOS, S (1977) "Eklogadion und Ecloga Privata aucta", VVAA., Fontes Minores II. Frankfurt am Main: V. Klostermann, pp. 45-86.

TOUBERT, P. (2006) "La teoría del matrimonio de los moralistas carolingios", en Toubert, P., Europa en su primer crecimiento: De Carlomagno al año mil .Trad. A. Domènech. Valencia: Universitat de València, pp. 254-287. La versión original se encuentra en: Toubert, P. (1977) "La théorie du mariage chez les moralistes carolingiens" en VVAA. Il matrimonio nella società altomedievale, Settimane di Studio del Centro Italiano di Studi sull'alto Medioevo 24. Spoleto: Centro italiano di studi sull' alto medioevo, pp. 233-285.

TOUBERT, P. (2006b) "La institución del matrimonio cristiano desde la Antigüedad tardía al año mil" Toubert, P. Europa en su primer crecimiento: De Carlomagno al año mil, Trad. A. Domènech. Valencia: Universitat de València, pp. 225-253.

TREgGIARI, S. (1993) Roman Marriage, iusti Coniuges From the Time of Cicero to the Time of Ulpian. Oxford: Oxford University Press.

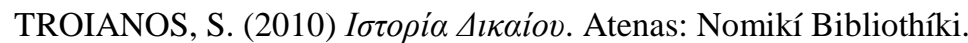

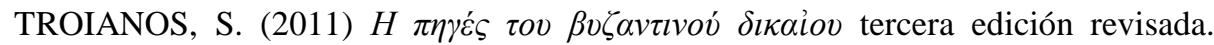
Atenas/Komotini: Sakkoula.

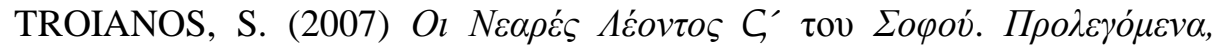

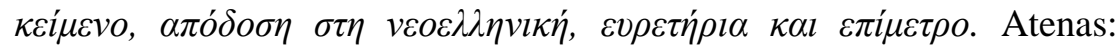

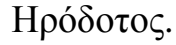

VIAL-DUMAS, M. (2015) "Notas sobre el Matrimonio en el oriente y occidente cristiano durante la Antigüedad tardía y el alto Medioevo", Ius Fugit 18.

VISMARA, G. (1988) “I rapporti patrimoniali tra coniugi nell'alto medioevo", en Vismara, G., Scritti di storia giuridica 5, La Famiglia. Milano: Giuffrè, pp. 141-189.

VOGEL, C. (1977) "Les rites de célébration du marriage: leur signification Dans la formation du lien durant la haut moyen âge", en VVAA., Il matrimonio nella società altomedievale, Settimane di Studio del Centro Italiano di Studi sull'alto Medioevo 24. Spoleto: Centro italiano di studi sull' alto medioevo, pp. 397-465. 
Manuel Vial D.: Modalidades del matrimonio tardoantiguo y altomedieval...

WICKHAM, C. (2005) Framing the Early Middle Ages: Europe and the Mediterranean, 400-800. Oxford-New York: Oxford University Press.

ZEUMER K. (1902) Liber iudiciorum sive Lex Visigothorum, M.G.H , Legum sectio I. Leges Nationum Germanicarum I., Leges Visigothorum. Hannover-Leipzig. 